\title{
Cultured Construction: Global Evidence of the Impact of National Values on Renewable Electricity Infrastructure Choice Jessica A. Kaminsky*
}

*Department of Civil and Environmental Engineering, University of Washington, 201

More Hall, Seattle, WA, 98195. Telephone +1.206.221.3058. Fax +1.206.543.1543. Emailjkaminsk@uw.edu.

\section{LIST OF SUPPORTING INFORMATION}

3 pages

Table SI1: Renewable electricity metrics and Hofstede's cultural dimensions 


\begin{tabular}{|c|c|c|c|c|c|c|c|c|}
\hline Nation & PDI $^{a}$ & IDV $^{\mathrm{a}}$ & MAS $^{a}$ & $\mathrm{UAI}^{\mathrm{a}}$ & $\begin{array}{c}\text { Percent } \\
\text { Renewable } \\
\text { Electricity } \\
(2010)^{\mathbf{b}}\end{array}$ & GDP $(2010)^{c}$ & $\begin{array}{l}\text { Electricity } \\
\text { Cost }^{d}\end{array}$ & $\begin{array}{c}\text { Grid } \\
\text { Outages }^{e}\end{array}$ \\
\hline Argentina & 49 & 46 & 56 & 86 & 1.77 & $\$ 293,697,869,717$ & no data & 3.5 \\
\hline Australia & 36 & 90 & 61 & 51 & 3.22 & $\$ 797,442,264,201$ & no data & no data \\
\hline Austria & 11 & 55 & 79 & 70 & 9.74 & $\$ 325,550,262,357$ & 0.199 & no data \\
\hline Bangladesh & 80 & 20 & 55 & 60 & 0.00 & $\$ 81,471,733,197$ & no data & 5.5 \\
\hline Belgium & 65 & 75 & 54 & 94 & 6.59 & $\$ 400,383,139,124$ & 0.214 & no data \\
\hline Brazil & 69 & 38 & 49 & 76 & 6.54 & $\$ 1,096,754,010,433$ & no data & 3.4 \\
\hline Bulgaria & 70 & 30 & 40 & 85 & 1.59 & $\$ 32,991,740,544$ & 0.083 & 1 \\
\hline Canada & 39 & 80 & 52 & 48 & 2.97 & $\$ 1,240,064,039,807$ & no data & no data \\
\hline Chile & 63 & 23 & 28 & 86 & 4.27 & $\$ 147,668,421,646$ & no data & 1.3 \\
\hline China & 80 & 20 & 66 & 30 & 1.67 & $\$ 3,839,284,159,376$ & no data & 1.3 \\
\hline Colombia & 67 & 13 & 64 & 80 & 0.95 & $\$ 182,893,446,718$ & no data & 1.8 \\
\hline Costa Rica & 35 & 15 & 21 & 86 & 17.53 & $\$ 25,017,792,423$ & no data & 1.7 \\
\hline Croatia & 73 & 33 & 40 & 80 & 1.23 & $\$ 45,872,253,522$ & 0.114 & 0.4 \\
\hline Czech Republic & 57 & 58 & 57 & 74 & 3.65 & $\$ 148,480,783,613$ & 0.15 & 0.6 \\
\hline Denmark & 18 & 74 & 16 & 23 & 31.95 & $\$ 256,817,427,642$ & 0.291 & no data \\
\hline Ecuador & 78 & 8 & 63 & 67 & 2.52 & $\$ 48,764,673,105$ & no data & 3.9 \\
\hline El Salvador & 66 & 19 & 40 & 94 & 30.21 & $\$ 18,341,273,340$ & no data & 7 \\
\hline Estonia & 40 & 60 & 30 & 60 & 7.84 & $\$ 13,897,254,467$ & no data & 0.1 \\
\hline Finland & 33 & 63 & 26 & 59 & 13.95 & $\$ 204,154,134,528$ & 0.154 & no data \\
\hline France & 68 & 71 & 43 & 86 & 2.79 & $\$ 2,204,446,339,914$ & 0.138 & no data \\
\hline Germany & 35 & 67 & 66 & 65 & 13.37 & $\$ 2,954,359,050,888$ & 0.253 & no data \\
\hline Greece & 60 & 35 & 57 & 112 & 5.34 & $\$ 240,951,131,470$ & 0.125 & no data \\
\hline Guatemala & 95 & 6 & 37 & 101 & 29.60 & $\$ 32,556,756,309$ & no data & 2.8 \\
\hline $\begin{array}{l}\text { Hong Kong SAR, } \\
\text { China }\end{array}$ & 68 & 25 & 57 & 29 & 0.00 & $\$ 220,058,248,223$ & no data & no data \\
\hline Hungary & 46 & 80 & 88 & 82 & 7.58 & $\$ 109,264,940,824$ & 0.168 & 1.8 \\
\hline India & 77 & 48 & 56 & 40 & 4.44 & $\$ 1,243,675,499,466$ & no data & 8.14 \\
\hline Indonesia & 78 & 14 & 46 & 48 & 5.60 & $\$ 377,898,889,670$ & no data & 2.2 \\
\hline Iran, Islamic Rep. & 58 & 41 & 43 & 59 & 0.07 & $\$ 242,702,371,179$ & no data & no data \\
\hline Ireland & 28 & 70 & 68 & 35 & 11.01 & $\$ 203,306,959,564$ & no data & no data \\
\hline Israel & 13 & 54 & 47 & 81 & 0.20 & $\$ 169,010,664,818$ & no data & 0.1 \\
\hline Italy & 50 & 76 & 70 & 75 & 8.65 & $\$ 1,763,885,790,470$ & 0.199 & no data \\
\hline Japan & 54 & 46 & 95 & 92 & 3.78 & $\$ 4,648,468,621,133$ & no data & no data \\
\hline $\begin{array}{l}\text { Korea, Rep. } \\
\text { (South) }\end{array}$ & 60 & 18 & 39 & 85 & 0.50 & $\$ 1,098,690,046,554$ & no data & no data \\
\hline Latvia & 44 & 70 & 9 & 63 & 1.74 & $\$ 15,502,642,580$ & 0.117 & 0.3 \\
\hline Lithuania & 42 & 60 & 19 & 65 & 7.43 & $\$ 27,476,518,251$ & 0.121 & 0.2 \\
\hline Luxembourg & 40 & 60 & 50 & 70 & 4.92 & $\$ 40,696,164,752$ & 0.168 & no data \\
\hline Malaysia & 104 & 26 & 50 & 36 & 1.02 & $\$ 178,672,208,075$ & no data & 3 \\
\hline Malta & 56 & 59 & 47 & 96 & 0.09 & $\$ 6,715,453,854$ & 0.17 & no data \\
\hline Mexico & 81 & 30 & 69 & 82 & 3.90 & $\$ 953,067,840,505$ & no data & 3.4 \\
\hline Morocco & 70 & 46 & 53 & 68 & 2.80 & $\$ 75,523,499,824$ & no data & 1.3 \\
\hline
\end{tabular}




\begin{tabular}{|c|c|c|c|c|c|c|c|c|}
\hline Nation & $\mathrm{PDI}^{\mathrm{a}}$ & IDV $^{\mathbf{a}}$ & MAS $^{a}$ & $\mathrm{UAI}^{\mathrm{a}}$ & $\begin{array}{c}\text { Percent } \\
\text { Renewable } \\
\text { Electricity } \\
(2010)^{\mathbf{b}}\end{array}$ & $\operatorname{GDP}(2010)^{c}$ & $\begin{array}{l}\text { Electricity } \\
\text { Cost }^{d}\end{array}$ & $\begin{array}{c}\text { Grid } \\
\text { Outages }^{\mathrm{e}}\end{array}$ \\
\hline Netherlands & 38 & 80 & 14 & 53 & 9.39 & $\$ 683,063,473,113$ & 0.174 & no data \\
\hline New Zealand & 22 & 79 & 58 & 49 & 18.09 & $\$ 121,173,448,020$ & no data & no data \\
\hline Norway & 31 & 69 & 8 & 50 & 1.00 & $\$ 315,796,662,786$ & 0.213 & no data \\
\hline Pakistan & 55 & 14 & 50 & 70 & 0.00 & $\$ 129,517,496,850$ & no data & 9.2 \\
\hline Panama & 95 & 11 & 44 & 86 & 0.30 & $\$ 22,603,329,668$ & no data & 2.1 \\
\hline Peru & 64 & 16 & 42 & 87 & 2.04 & $\$ 103,487,662,932$ & no data & 3.2 \\
\hline Philippines & 94 & 32 & 64 & 44 & 14.78 & $\$ 131,131,009,140$ & no data & 3.9 \\
\hline Poland & 68 & 60 & 64 & 93 & 5.07 & $\$ 383,205,737,634$ & 0.147 & 2.8 \\
\hline Portugal & 63 & 27 & 31 & 104 & 22.73 & $\$ 197,164,604,093$ & 0.165 & no data \\
\hline Romania & 90 & 30 & 42 & 90 & 0.69 & $\$ 114,088,972,369$ & 0.108 & 1.3 \\
\hline $\begin{array}{l}\text { Russian } \\
\text { Federation }\end{array}$ & 93 & 39 & 36 & 95 & 0.05 & $\$ 909,241,662,712$ & no data & 2 \\
\hline Serbia & 86 & 25 & 43 & 92 & 0.00 & $\$ 27,876,766,883$ & no data & 1.1 \\
\hline Singapore & 74 & 20 & 48 & 8 & 2.80 & $\$ 176,457,991,287$ & no data & no data \\
\hline Slovak Republic & 104 & 52 & 110 & 51 & 2.49 & $\$ 77,075,641,089$ & 0.168 & 0.2 \\
\hline Slovenia & 71 & 27 & 19 & 88 & 1.42 & $\$ 38,970,326,905$ & 0.144 & 0.6 \\
\hline Spain & 57 & 51 & 42 & 86 & 18.59 & $\$ 1,179,232,117,936$ & 0.198 & no data \\
\hline Sweden & 31 & 71 & 5 & 29 & 10.58 & $\$ 401,624,584,927$ & 0.209 & no data \\
\hline Switzerland & 34 & 68 & 70 & 58 & 2.12 & $\$ 427,575,024,211$ & no data & no data \\
\hline Thailand & 64 & 20 & 34 & 64 & 2.14 & $\$ 210,090,542,914$ & no data & 1.5 \\
\hline $\begin{array}{l}\text { Trinidad and } \\
\text { Tobago }\end{array}$ & 47 & 16 & 58 & 55 & 0.00 & $\$ 18,988,955,441$ & no data & 0.4 \\
\hline Turkey & 66 & 37 & 45 & 85 & 1.85 & $\$ 565,091,528,615$ & 0.122 & 4.7 \\
\hline United Kingdom & 35 & 89 & 66 & 35 & 5.86 & $\$ 2,360,033,739,558$ & 0.143 & no data \\
\hline United States & 40 & 91 & 62 & 46 & 4.10 & $\$ 13,595,644,353,592$ & no data & no data \\
\hline Uruguay & 61 & 36 & 38 & 100 & 8.69 & $\$ 22,899,299,770$ & no data & 0.3 \\
\hline Venezuela, RB & 81 & 12 & 73 & 76 & 0.00 & $\$ 174,552,448,164$ & no data & 8.3 \\
\hline Vietnam & 70 & 20 & 40 & 30 & 0.11 & $\$ 78,282,167,938$ & no data & 3.6 \\
\hline
\end{tabular}

${ }^{a}$ Hofstede, G. Geert Hofstede | Hofstede Dimension Data Matrix. http://geert-hofstede.com/dimensions.html

b World Bank. 2010 Electricity Production from Renewable Sources, Excluding Hydroelectric (\% of Total).

http://data.worldbank.org/indicator

c World Bank. 2010 GDP (Constant 2005 US\$). http://data.worldbank.org/indicator

d IEA. Energy Prices and Taxes: Quarterly Review 2014.

http://www.eia.gov/totalenergy/data/monthly/previous.cfm.

e World Bank. Value Lost Due to Electrical Outages (\% of Sales). http://data.worldbank.org/indicator 